\title{
Tissue Concentrations of Clozapine and its Metabolites in the Rat
}

\author{
Ross J. Baldessarini, M.D., Franca Centorrino, M.D., James G. Flood, Ph.D., \\ Sheila A. Volpicelli, B.S., David Huston-Lyons, Ph.D., and Bruce M. Cohen, M.D., Ph.D.
}

Clozapine (CLZ) and its metabolites norclozapine (NOR) and clozapine-N-oxide (NOX) were assayed in rat serum and brain tissue after intraperitoneal injection of CLZ. Clozapine levels rose with dose, averaging $28 \mathrm{ng} / \mathrm{ml}$ (87 $\mathrm{nmol} / \mathrm{L}$ ) serum per milligram/kilogram dose. Brain- and serum-CLZ levels correlated closely, averaging 24-fold higher in brain. Norclozapine and NOX averaged approximately $58 \%$ and $13 \%$ of CLZ in serum, respectively, whereas in brain, NOR was detected only at doses greater than or equal to $10 \mathrm{mg} / \mathrm{kg}$ (approximately $5.6 \%$ of CLZ) and NOX was undetectable. Levels peaked within 30 minutes, and elimination of CLZ from brain and CLZ or NOR from blood was very rapid (half-life = 1.5 to 1.6 hours). A week of daily dosing with CLZ led to no accumulation of drug in brain; a week of fluoxetine pretreatment increased analyte concentrations (serum, $86 \%$; brain, 61\%), but valproate had little effect.

[Neuropsychopharmacology 9:117-124, 1993]
KEY WORDS: Clozapine; Clozapine-N-oxide; Drug assay; Fluoxetine; Liquid chromatography; Norclozapine; Photodiode-array; Spectrophotometry; Valproic acid

Despite its invention in 1960 and its clinical use for more than two decades, information on the disposition and metabolism of the atypical antipsychotic drug clozapine (CLZ) remains limited, and guidelines for clinical application and interpretation of plasma assays of CLZ or its metabolites are not well established (Baldessarini and Frankenburg 1991). Several clinical studies of circulating concentrations of CLZ and its prominent metabolites norclozapine (NOR) and clozapine-N-oxide (NOX) using contemporary analytical methods have been reported and were reviewed recently by Volpicelli and colleagues (1993). Reports in-

From the Consolidated Department of Psychiatry and Neuroscience Program, Harvard Medical School and Mailman Research Center of McLean Hospital (RJB, FC, DH-L, BMC); and Department of Pathology, Harvard Medical School and Clinical Chemistry Laboratory of the Massachusetts General Hospital (JGF, SAV), Boston, Massachusetts.

Address correspondence to: Dr. Ross J. Baldessarini, Mailman Research Center, McLean Hospital, 115 Mill Street, Belmont, MA 02178.

Received January 28, 1993; revised April 12, 1993; accepted April 16, 1993. dicate that serum concentrations of CLZ have ranged from 60 to $600 \mathrm{ng} / \mathrm{ml}$ at about 12 hours after daily clinical doses of CLZ of 100 to $500 \mathrm{mg}$. Circulating levels of the metabolite NOR in man often approach those of CLZ itself (averaging approximately $75 \%$ to $90 \%$, but ranging widely (from approximately $10 \%$ to over $100 \%)$, whereas concentrations of NOX have been consistently lower (typically, $10 \%$ to $35 \%$ of CLZ). Elimination half-life $\left(t_{1 / 2[\beta]}\right)$ of CLZ from human plasma has been reported to average approximately 8 to 12 hours (Baldessarini and Frankenburg 1991).

There are recent indications that CLZ may interact with other agents in man, with decreases in circulating concentrations associated with smoking (Haring et al. 1990) and treatment with phenytoin (Miller et al. 1991), and increases associated with cimetidine (Szymanski et al. 1991) and fluoxetine (Centorrino et al. 1993b), whereas valproate appears to have lesser effects (Centorrino et al. 1993b). Clozapine levels also rise predictably with dose (Kane et al. 1981; Haring et al. 1990; Centorrino et al. 1933a) and with age (Haring et al. 1990) and tend to be slightly higher in women, even on a dose-and-weight-corrected basis to account for typically higher milligram/kilogram doses in men (Haring et al. 1990; Centorrino et al. 1993a). 
Typical plasma concentrations associated with clinical responses are approximately 200 to $400 \mathrm{ng} / \mathrm{ml}$ or 50 to $100 \mathrm{ng} / \mathrm{ml}$ per milligram/kilogram dose (Choc et al. 1990; Baldessarini and Frankenburg 1991; Centorrino et al. 1993a). There are preliminary indications that plasma concentrations of CLZ above $350 \mathrm{ng} / \mathrm{ml}$ may increase the likelihood of a favorable clinical response (Perry et al. 1991). Levels substantially above $1,000 \mathrm{ng} / \mathrm{ml}$ may increase the risk of central or systemic toxicity (Szymanski et al. 1991), including seizures (Simpson and Cooper 1978). Taken together, these findings suggest that assays of circulating levels of CLZ or its metabolites may have some clinical utility in guiding dose selection or limiting toxic risks.

In contrast, by extensive computer-assisted searches of the international literature, we could find very few studies of CLZ or its metabolites and their disposition in the brain or blood in laboratory animals. The few studies of rat either used analytical methods that did not separate CLZ and its metabolites (Gauch and Michaelis 1970; Gardiner et al. 1978) or evaluated a limited range of pharmacologically relevant conditions (Wilk and Stanley 1978). Because little is known about the pharmacokinetics (or the biological activity) of the prominent metabolites of CLZ, particularly in laboratory animals, we applied recently improved assay methods to study systematically the disposition of CLZ and its metabolites NOR and NOX in rat. The assays used for CLZ, NOR, and NOX (Volpicelli et al. 1993) are among the most sensitive and selective methods now available, with high recoveries and sensitivity of 3 to $4 \mathrm{ng} / \mathrm{ml}$ ( 9 to $12 \mathrm{pmol} / \mathrm{ml}$ ) that are similar to limits of detection found with mass spectrometric methods (Bondesson and Lindström 1988).

\section{METHODS}

Animal Subjects were adult, male Sprague-Dawley rats weighing between 250 and $300 \mathrm{~g}$ (Charles River Labs., Wilmington, MA), adapted to the laboratory environment for at least a week prior to use and housed 4 per cage in a temperature- and humiditycontrolled environment under a 12-hour lighting cycle (07:00 to 19:00), as described elsewhere (Cohen et al. 1992). Animal procedures were reviewed and approved by the Institutional Animal Care and Use Committee (IACUC) of McLean Hospital for compliance with federal and local regulations.

Rats were given CLZ (base, $\mathrm{MW}=326.8$ ) or other test agents (dissolved in $50 \%$ dimethylsulfoxide or a few drops of $85 \%$ [w/v] lactic acid diluted to injection volume with purified water) by intraperitoneal (IP) injections of 0.25 to $0.30 \mathrm{ml}$, with controls given matched vehicle. Other agents included fluoxetine hydrochloride ( $\mathrm{MW}=345.8$; donated by Eli Lilly Laboratories, In-
Clozapine

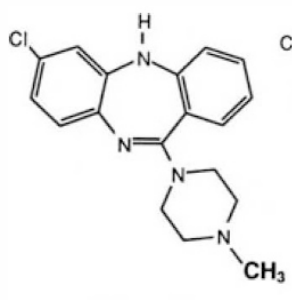

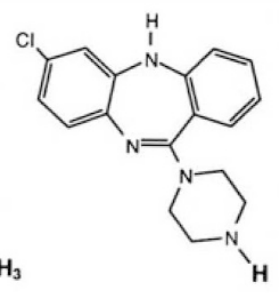

Norclozapine

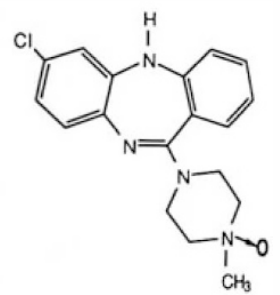

Clozapine-N-Oxide
Figure 1. Chemical structures of clozapine and metabolites. Clozapine (CLZ) is 8-chloro-11-(4-methyl-1-piperazinyl)-5H-benzo[b,e][1,4]diazepine $\left(\mathrm{C}_{18} \mathrm{H}_{19} \mathrm{~N}_{4} \mathrm{Cl} ; \quad \mathrm{MW}=\right.$ 326.8); norclozapine (NOR; $\mathrm{MW}=312.8$ ) is $\mathrm{N}$-desmethylclozapine. Clozapine-N-oxide (NOX; $\mathrm{MW}=342.8$ ) is oxidized but not $\mathrm{N}$-desmethylated.

dianapolis, IN), phenytoin sodium salt (5,5-diphenyl2,4-imidazolidinedione sodium, $\mathrm{MW}=274.2$; Research Biochemicals, Inc., Natick, MA), and valproic acid sodium salt (2-propylpentanoic acid sodium, MW = 166.2; Sigma Chemicals, St. Louis, MO).

Samples of rat serum and brain tissue were assayed for CLZ and its metabolites, NOR and NOX (structures in Fig. 1) by highly selective, reversedphase liquid chromatographic separation, with sensitive detection at either $254 \mathrm{~nm}$ or by photodiode-array multiwavelength (210 to $340 \mathrm{~nm}$ ) ultraviolet spectrophotometry (Volpicelli et al. 1993). When appropriate, spectra of peaks in samples were compared by computer to those of authentic standards as well as a large number of other agents to minimize the risk of interference by other drugs, including fluoxetine.

The methods to determine concentrations of $\mathrm{CLZ}$ and its metabolites NOR and NOX in rat serum were virtually identical to those detailed earlier for human serum samples, using $600 \mu \mathrm{l}$ of serum extracted into ethyl acetate and back into $0.1 \mathrm{~N} \mathrm{HCl}$ to provide $50 \mu \mathrm{l}$ aliquots for assay (Centorrino et al. 1993; Volpicelliet al. 1993). Recovery of CLZ and NOR (at $400 \mathrm{ng} / \mathrm{ml}$ ) and of NOX $(100 \mathrm{ng} / \mathrm{ml})$ from control serum averaged $76 \%$, $80 \%$, and $67 \%$ ( $n=5$ samples), respectively, and the interassay coefficient of variation ( $\mathrm{CV}=\mathrm{SD} /$ mean) for independent assays ( $n=16$ samples) averaged $2.0 \%$, $2.5 \%$, and $2.2 \%$, respectively.

To determine rat brain tissue levels of CLZ and its derivatives, a weighed portion of tissue (approximately $30 \mathrm{mg}$ of striatum or cerebral cortex) was suspended in $1.0 \mathrm{ml}$ of $0.5 \mathrm{M}$ citric acid, sonicated on ice for 5 minutes, and then centrifuged at $10,000 \mathrm{~g}$ for 15 minutes. The supernatant citric acid extract was kept frozen at $-70^{\circ} \mathrm{C}$ until assayed (within 2 weeks) by the same methods used for serum samples, with slight modifications. These included the use of $0.5 \mathrm{M}$ citric acid (instead of drug-free serum) as the vehicle for all assay standards and controls, with $300 \mu$ l of superna. tant mixed with $100 \mu$ lof $5 \mathrm{M}$ aqueous $\mathrm{NaOH}$. With these modifications, recovery of CLZ and NOR (at 200 


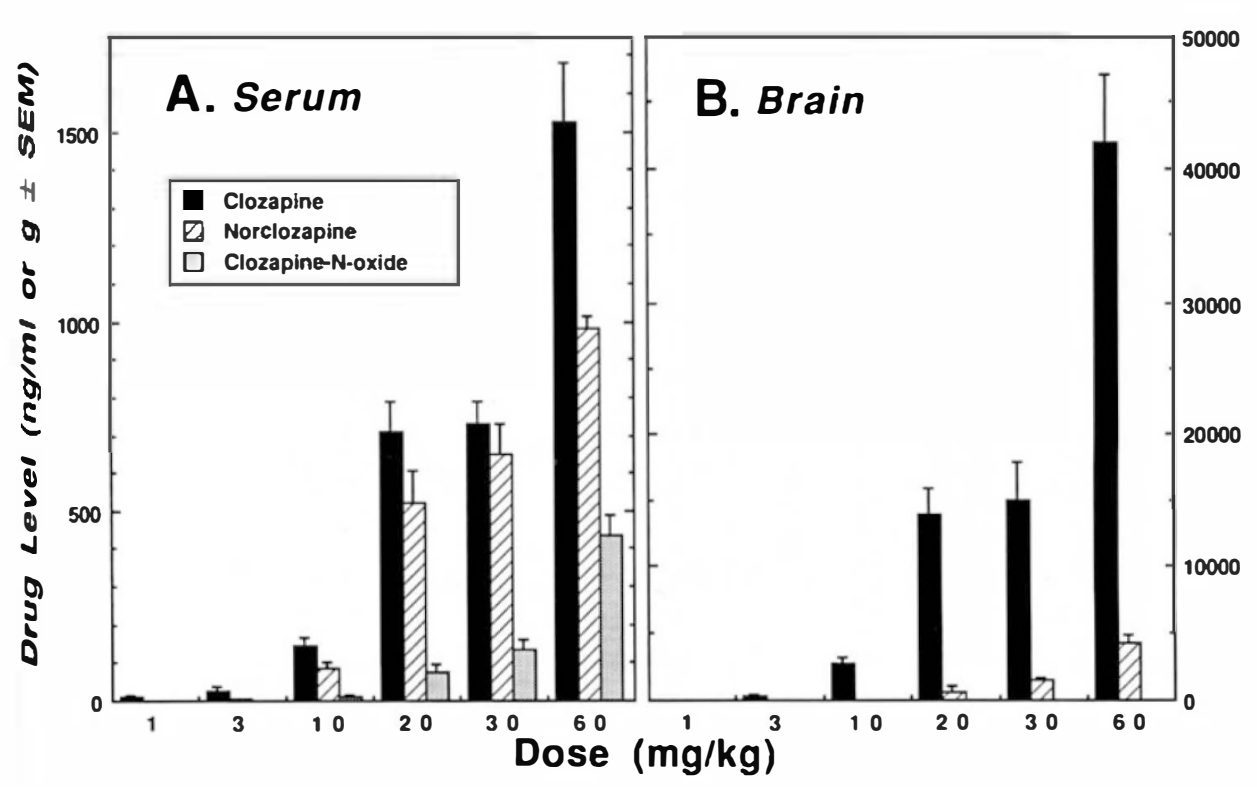

Figure 2. Effect of dose on tissue levels of CLZ and its metabolites. Shown are mean $\pm \operatorname{SEM}(n=6$ to 8 rats) concentrations of CLZ (black bars) and its metabolites, NOR (striped bars) and NOX (shaded bars) in rat serum (A, in $\mathrm{ng} / \mathrm{ml}$ ) and brain corpus striatum (B, in $\mathrm{ng} / \mathrm{g}$ ) at 1 hour after acute doses of CLZ from 1 to $60 \mathrm{mg} / \mathrm{kg}$ IP. NOX was not detected in brain after any dose. $\mathrm{ng} / \mathrm{ml}$ ) and of NOX (50 ng/ml) was $94 \%, 96 \%$, and $100 \%$, respectively, while recovery of an internal standard (triprolidine; Sigma Chemicals, St. Louis, MO) was $90 \%$ (all $n=5$ ). Interrun precision (CV) for independently replicated assays of the same samples at these analyte concentrations was $3.2 \%, 4.2 \%$, and $6.8 \%$, respectively; precision $(\mathrm{CV})$ for CLZ and NOR (at $400 \mathrm{ng} / \mathrm{ml}$ ) and of NOX (at $100 \mathrm{ng} / \mathrm{ml}$ ) was similar at $3.8 \%, 3.6 \%$, and $5.3 \%$, respectively (all $n=21$ ). Limits of detection of the three drug analytes were 3 $\mathrm{ng}$ to $4 \mathrm{ng}$ per milliliter of serum or approximately 4 $\mathrm{ng} / \mathrm{g}$ to $7 \mathrm{ng} / \mathrm{g}$ brain tissue, and about $560 \mathrm{pg}$ (1.7 pmol) per injected sample.

Data (presented as means \pm SEM unless stated otherwise) were analyzed by one-way analysis of variance ANOVA of individual values to establish a significant $(p<.05)$ overall effect of treatment condition on analyte concentration and then by post-hoc Scheffé tests or Mann-Whitney nonparametric U-tests for ratio data, with significance $(p<.05)$ based on twotailed critical values. Tissue half-life (with its SE and $95 \%$ confidence interval $[95 \% \mathrm{CI}]$ ) was estimated as $\mathrm{t}_{1 / 2}=\ln 2 /-\mathrm{k}$, with the rate constant $(\mathrm{k})$ computed as slope obtained by regressing $\ln \left(\log _{e}\right)$ tissue CLZ concentration versus time after attaining peak tissue concentration, as reported previously (Cohen et al. 1992). Correlations were tested by linear regression (to obtain coefficient, $r$, as well as slope $\pm \mathrm{SE}$, with $95 \% \mathrm{CI}$ ) or the nonparametric Spearman rank method (for $r_{\mathbf{s}}$ ). Computations used the Statview program for the MacIntosh microcomputer (Abacus Concepts, Inc., Berkeley, CA).

\section{RESULTS}

Concentrations of CLZ and its major metabolites, NOR and NOX and total analyte levels in rat serum

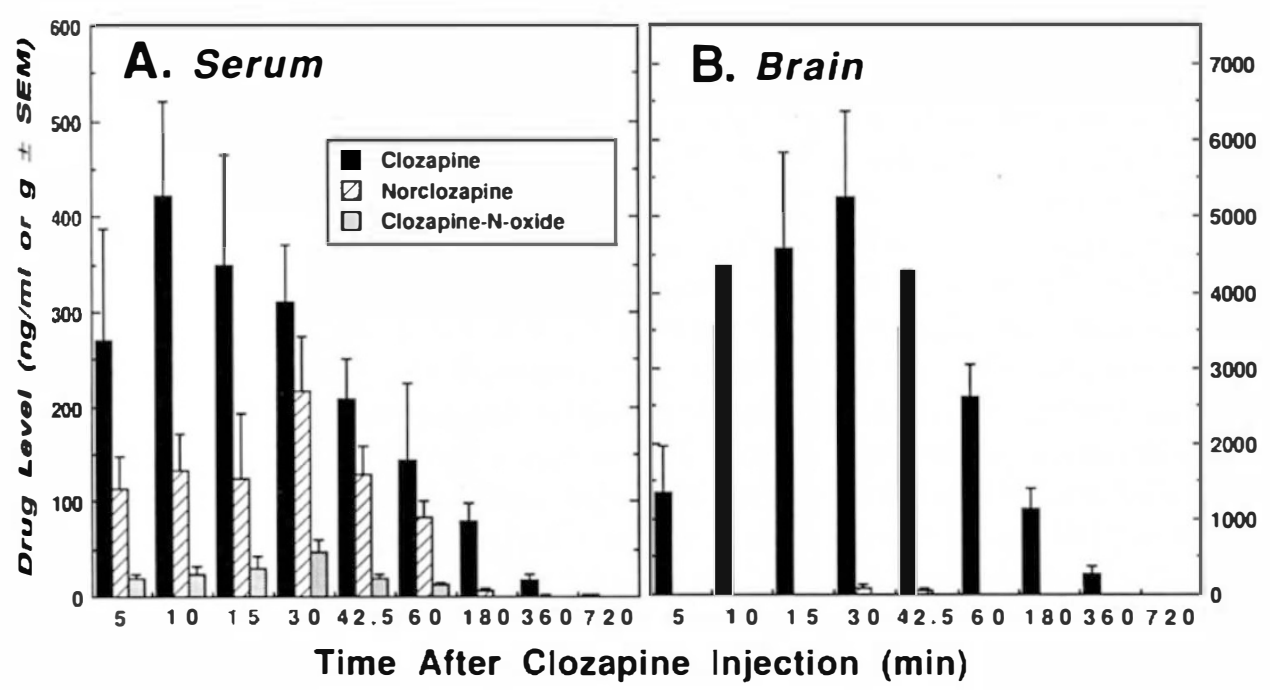

Figure 3. Time course of tissue levels of CLZ and its metabolites. Shown are mean $\pm \operatorname{SEM}(n=6$ to 8 rats $)$ concentrations of CLZ and its metabolites, NOR and NOX in rat serum $(\mathbf{A}$, in $\mathrm{ng} / \mathrm{ml}$ ) and brain corpus striatum (B, in $\mathrm{ng} / \mathrm{g})$ at times from 5 minutes to 12 hours after an acute dose of CLZ (10 mg/kg IP). NOX was not detected in brain at any time, and levels of CLZ and NOR were undetectable in blood or brain after any dose at 24 hours to 72 hours (not shown). 


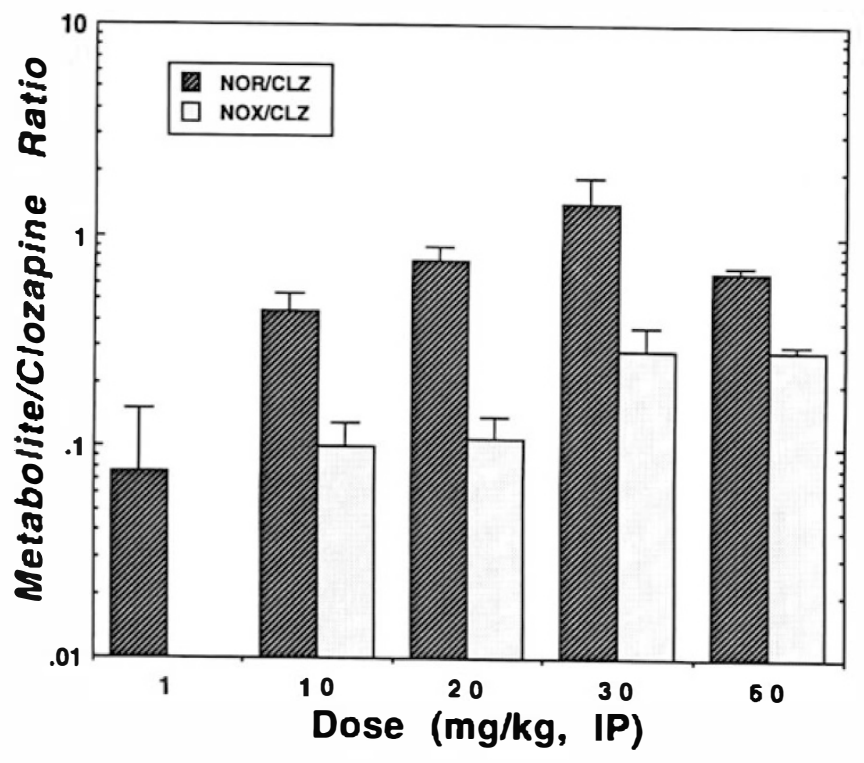

Figure 4. Effect of dose of CLZ on metabolite:CLZ ratios in serum. Data are mean \pm SEM ratios of NOR/CLZ (striped bars) and NOX/CLZ (light bars) for serum at less than or equal to 1 hour for a range of doses of CLZ. The effect of dose is highly significant for both ratios (for NOR/CLZ, $F[4,50]=$ $6.26, p=.0004$; for NOX/CLZ, $F[4,50]=5.18, p=.0014)$ and individual ratio measures are highly correlated with dose (NOR/CLZ: $r_{s}=0.678, p \leqslant .0001$; NOX/CLZ: $r_{s}=0.758$, $p \leqslant .0001)$.

and brain (striatum) were highly dose dependent (Fig. $2 ; r$ and $r_{\mathrm{s}}$ all $\left.>0.95\right)$. Following a $10-\mathrm{mg} / \mathrm{kg}$ IP dose of CLZ, peak CLZ levels were reached very rapidly (Fig. 3 ) in serum (10 minutes) and somewhat later (30 minutes) in brain, as were NOR levels ( 30 minutes) in serum and brain. Clozapine levels in serum, across all doses and times to 1 hour ( $n=9$ conditions), averaged $28.4 \pm 2.8 \mathrm{ng} / \mathrm{ml}(86.8 \pm 8.7 \mathrm{nM})$ per $\mathrm{mg} / \mathrm{kg}$ dose.

The ratio of NOR to $C L Z$ in serum ranged from very low or trace values of NOR at a low dose of CLZ $(1 \mathrm{mg} / \mathrm{kg}$ ) or at late times ( $\geqslant 1$ hour) to $17.1 \% 1$ hour after $3 \mathrm{mg} / \mathrm{kg}$ and higher values averaging $52.2 \pm$ $5.57 \%$ up to 1 hour after a dose of $10 \mathrm{mg} / \mathrm{kg}$, with further increases to an average of $75.9 \%$ at doses greater than or equal to $20 \mathrm{mg} / \mathrm{kg}$. Similar dose-dependent increases in the ratio of NOX to CLZ at 1 hour after dosing were also found in serum, ranging from undetectable or trace levels at less than $10 \mathrm{mg} / \mathrm{kg}$ to $9.2 \pm 1.4 \%$ after $10 \mathrm{mg} / \mathrm{kg}, 10.5 \%$ after $20 \mathrm{mg} / \mathrm{kg}, 18.7 \%$ after 30 $\mathrm{mg} / \mathrm{kg}$, and $28.7 \%$ after $60 \mathrm{mg} / \mathrm{kg}$ doses of CLZ. In brain tissue (striatum), NOR was not detectable after doses of CLZ less than $10 \mathrm{mg} / \mathrm{kg}$ or times greater than 60 minutes and was found only in minor concentrations (averaging $1.34 \pm 0.15 \%$ of CLZ levels) less than or equal to 1 hour after higher doses $(10 \mathrm{mg} / \mathrm{kg}$ to 60 $\mathrm{mg} / \mathrm{kg}$ ), whereas NOX was not detectable in brain at any time or dose (Figs. 2 and 3). The significantly dosedependent nature of the ratios of NOR and NOX to

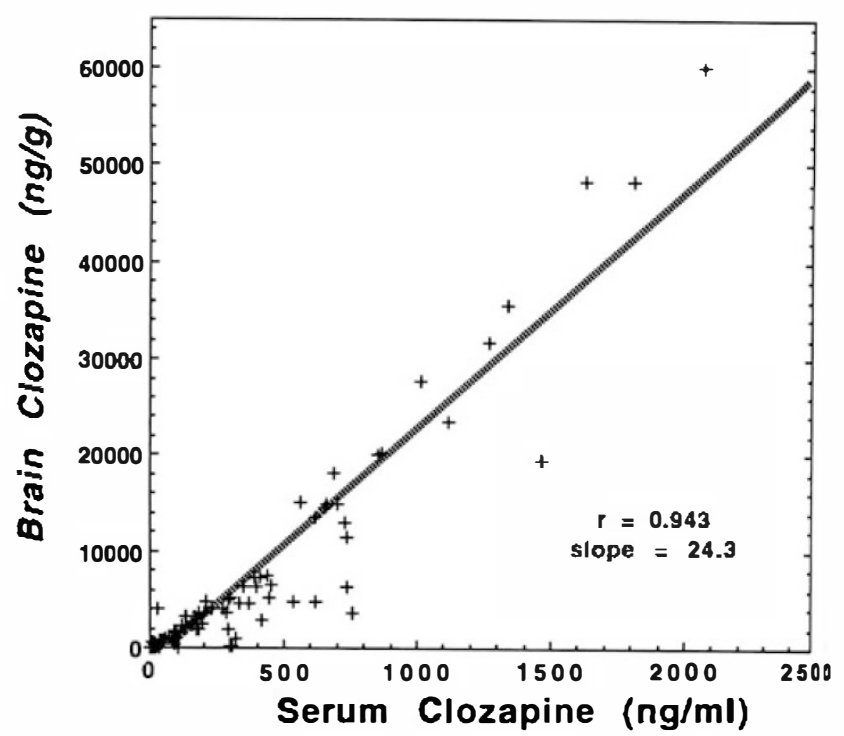

Figure 5. Correlation of rat brain versus serum concentrations of CLZ. Data are individual values at all doses and times shown in Figs. 1 and 2 ( $n=103$ rats). The relationship shown indicates a high overall linear correlation $(r=0.943$, $p<.0001)$ that is sustained by nonparametric correlation $\left(r_{s}=0.922, p<.0001\right)$ and indicates that brain concentration of CLZ averaged 24.3 times higher than the corresponding serum drug level; however, the relationship may not be linear because brain CLZ levels less than or equal to $5 \mu \mathrm{g} / \mathrm{g}$ averaged only 7.2 times higher than in serum, whereas the brain:blood ratio for brain CLZ levels greater than $5 \mu \mathrm{g} / \mathrm{g}$ (29.2) was much higher.

their precursor CLZ is summarized in Fig. 4, with statistical analyses based on ratios for assays of serum samples for individual rats.

CLZ levels from all individual subjects shown in Figs. 2 and 3 yielded a close linear correlation (Fig.5) between brain and serum $(r=0.943, p<.0001)$ that is sustained by nonparametric correlation $\left(r_{\mathrm{s}}=0.922\right.$, $p<.0001)$. Inclusions of all points indicates that brain concentration of CLZ averaged 24.3 times (as slope; $95 \% \mathrm{CI}=22.6$ to 25.9 ) higher than the corresponding serum drug level. However, the relationship may not be linear because brain CLZ levels less than or equal to $5 \mu \mathrm{g} / \mathrm{g}$ averaged only 7.2 times higher than in serum (95\% CI $=5.56$ to 8.82$)$, whereas the brain:blood ratio for CLZ levels greater than $5 \mu \mathrm{g} / \mathrm{g}$ was 3.64 times higher, at $29.2(95 \% \mathrm{CI}=25.1$ to $33.3, p<.001)$.

Elimination of CLZ was similarly rapid from brain and blood. Computed elimination half-life ( $t t_{2}[\beta]$, based on data shown in Fig. 3 through the latest times following peak levels that provided reliably detectable tissue drug concentrations (out to $12 \mathrm{~h}$ ), was 1.64 hours in serum and 1.51 hours in brain (striatum). Elimination of NOR from serum also was rapid $\left(t_{1 / 2[\beta]}=\right.$ 1.57 hours (Table 1). Similarly evaluated early (appa: ent distribution phase) kinetics showed indistinguish. able, short half-life values for CLZ from serum and 
Table 1. Kinetics Computations

\begin{tabular}{lcc}
\hline & \multicolumn{2}{c}{ Half-Life $^{\star}\left(\mathrm{t}_{1 / 2}\right) \pm$ SE (h) } \\
\cline { 2 - 3 } Measure & Distribution $(\boldsymbol{\alpha})$ & Elimination $(\boldsymbol{\beta})$ \\
\hline Serum CLZ & $\mathbf{0 . 5 4 8} \pm 0.055$ & $\mathbf{1 . 6 3 9} \pm 0.066$ \\
$(95 \%$ CI) & $(0.416-0.805)$ & $(1.398-1.980)$ \\
Serum NOR & $\mathbf{0 . 4 9 7} \pm 0.026$ & $\mathbf{1 . 5 6 8} \pm 0.177$ \\
(95\% CI) & $(0.407-0.639)$ & $(0.640-3.483)$ \\
Brain CLZ & $\mathbf{0 . 5 0 7} \pm 0.094$ & $\mathbf{1 . 5 1 0} \pm 0.059$ \\
$(95 \%$ CI) & $(0.151-0.372)$ & $(1.013-2.950)$ \\
\hline
\end{tabular}

- Half-life values were computed from regression functions of $\ln$ [analyte] concentration vs. time (h), as $t_{1 / 2}=(\ln 2) /(-$ slope $)$.

brain and for NOR from serum $(t / 2[\alpha]=0.50$ to 0.55 hours; Table 1).

Repeated daily treatment $(n \geqslant 12$ rats per condition) with CLZ ( $10 \mathrm{mg} / \mathrm{kg}$ twice daily) for 7 days (sampled at 4 hours after the final morning dose of 10 $\mathrm{mg} / \mathrm{kg}$ ) led to cerebral cortical levels of CLZ + NOR averaging $1,057 \pm 270 \mathrm{ng} / \mathrm{g}$, while a single acute dose $(10 \mathrm{mg} / \mathrm{kg}$ ) yielded a value of $1,037 \pm 157 \mathrm{ng} / \mathrm{g}$ at 4 hours, representing an insignificant difference of less than $2 \%$. This observation indicates a lack of significant cerebral accumulation of CLZ or its metabolites in rat brain tissue under the conditions tested.

Pretreatment with the antidepressant fluoxetine $(10 \mathrm{mg} / \mathrm{kg} /$ day for 7 days) led to significant increases in serum concentrations of CLZ, NOR, NOX, and their total (Fig. 6), by $86.4 \%, 74.9 \%, 146.4 \%$, and $85.2 \%$, respectively, following a challenge dose of CLZ
(1 hour after $20 \mathrm{mg} / \mathrm{kg}$ ) on day 8 . Brain levels also tended to be higher (total drug analytes [CLZ + NOR] in striatum raised by $61.4 \%$ ) and NOX remained undetectable. Similar daily pretreatment with the antimanic-anticonvulsant valproic acid $(20 \mathrm{mg} / \mathrm{kg})$ led to smaller, statistically nonsignificant changes in tissue levels of CLZ and its metabolites (serum and striatal total analyte concentrations decreased by $35.3 \%$ and $53.9 \%$, respectively). After fluoxetine, there was no significant effect on the serum NOR:CLZ ratio $(0.709$ $\pm 0.055)$ compared to vehicle-pretreated controls $(0.580 \pm 0.153)$, but pretreatment with valproate, unaccountably, raised the value (by 3.72-fold, to $2.16 \pm$ $0.65)$ significantly $\left(\mathrm{U}^{\prime}=48.0, p=.003\right)$. (Vehicle controls in this experiment were included with the dose data in Fig. 2 as an independent confirmatory condition.)

\section{DISCUSSION}

Some of the observations arising from the present investigation could be anticipated from findings in early studies of laboratory animals. A particularly noteworthy early report included studies of metabolism and distribution of radiolabeled ${ }^{3} \mathrm{H}-\mathrm{CLZ}$ in mouse, dog, and human subjects (Gauch and Michaelis 1970). In that report, radioactive material derived from tritiated CLZ (not separated or otherwise identified as CLZ or its metabolites) was found in approximately fivefold

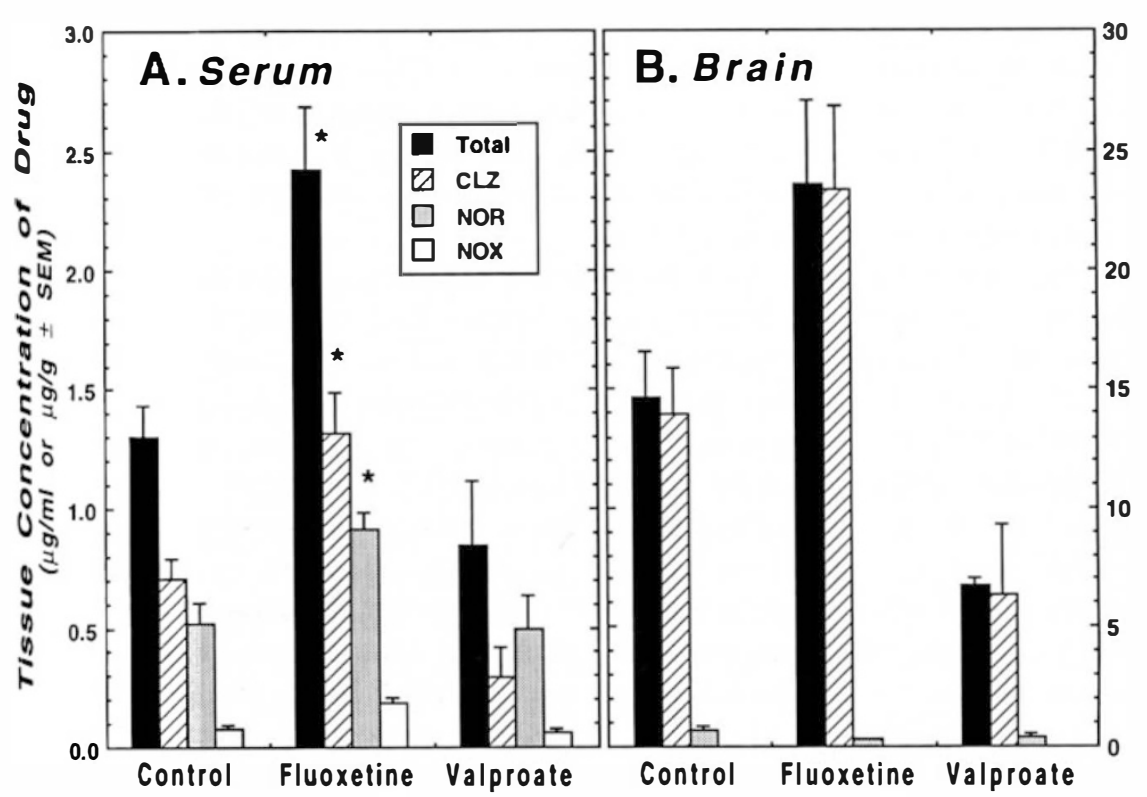

Figure 6. Effects of repeated pretreatment with fluoxetine or valproate on serum (A) and brain (B) concentrations of CLZ and its metabolites. Data are mean \pm SEM concentrations of CLZ (striped bars), its metabolites NOR (light bars) and NOX (white bars), and the total of all of these analytes (black bars) for $\boldsymbol{n}=7$ rats per condition. Rats were treated with fluoxetine $(10 \mathrm{mg} / \mathrm{kg})$, valproate $(20$ $\mathrm{mg} / \mathrm{kg}$ ), or control vehicle, daily for 7 days. Analysis of variance for overall effects of pretreatments on each analyte (as $F[2,18]$ ) were as follows: Serum: all analytes $(F=12.2, p=.0004)$, $\operatorname{CLZ}(F=15.5, p<.0001), \operatorname{NOR}(F=$ $5.17, p=.017), \operatorname{NOX}(F=9.79, p=$ .0013). Brain: all analytes $(F=8.48$, $p=.0025), \operatorname{CLZ}(F=9.00, p=.002)$, NOR $(F=2.57, p=.10)$, NOX (not detected). Post-hoc significant differences ( $p<.05$; asterisks) from vehiclepretreated controls were found only for fluoxetine in serum (with similar trends in brain). 
higher concentrations in mouse brain than in serum (at 1 and 8 hours after a total dose of $50 \mathrm{mg} / \mathrm{kg}$, PO). Levels remained detectable in those compartments at 1 hour and 8 hours, but not at 24 hours. Levels in mouse fat, lung, kidney, liver, and bile were greater than or equal to 10 times higher than in brain and could be detected at 24 hours. Also in mouse, radioactive drug disappeared very rapidly after intravenous administration and could not be detected for more than 4 hours after a total dose of ${ }^{3} \mathrm{H}-\mathrm{CLZ}$ of $10 \mathrm{mg} / \mathrm{kg}$, with a half-life possibly as short as 1 hour. In dog, a compound identified as ${ }^{3} \mathrm{H}-\mathrm{NOX}$ was found as the main circulating metabolite of ${ }^{3} \mathrm{H}-\mathrm{CLZ}$, representing approximately $30 \%$ of CLZ concentrations (which were approximately $5 \mu \mathrm{g} / \mathrm{ml}$ at 1 hour after a total oral dose of $50 \mathrm{mg} / \mathrm{kg}$ ), whereas the ${ }^{3} \mathrm{H}-\mathrm{NOR}$ metabolite was detected only in trace amounts in that species. For human subjects, information on serum concentrations of CLZ was not provided, but urine and feces were found to contain material identified semiquantitatively by solvent extraction, thin-layer chromatographic separation, and colorimetric detection as including NOR and NOX as well as CLZ.

Taken together, this early work strongly suggested significant species differences in the metabolism of CLZ, in that mouse produced relatively large amounts of NOR, whereas dog tended to oxidize CLZ to NOX very efficiently, and man appeared to produce both NOR and NOX. Also, the rodent species showed substantial accumulation of drug material in brain over blood, with suggestions of a short half-life from both tissues - all in accord with findings in rat in the present study using contemporary analytical methods.

A later study in the rat (Gardiner et al. 1978) applied a quantitative fluorimetric detection procedure, following extraction into toluene isoamylol from alkaline borate-buffered aqueous tissue homogenates, and back extraction into $0.1 \mathrm{~N} \mathrm{HCl}$. Clozapine, NOR, and NOX also were identified qualitatively by separation on silica gel thin-layer chromatographic sheets and visualization with ultraviolet light. After a $20-\mathrm{mg} / \mathrm{kg}$ IP dose of CLZ, the brain:blood concentration ratio of "CLZ-like" material was 16.0:1.3 (12-fold) and 4.6:1.1 $\mu \mathrm{g} / \mathrm{g}$ (4.2-fold) at 1 hour and 6 hours - again, generally consistent with our present findings with improved assay methods. Even higher concentrations of drug material (4.0 times higher than in brain at 1 hour and 11.3-fold higher at 6 hours) were found in rat lung tissue (Gardiner et al. 1978). The possible pharmacologic significance of this and other relatively highly accumulating and slowly cleared pools (found also in liver, bile, fat, and kidney by Gauch and Michaelis [1970] in mouse) is not clear. Specifically, evidence of late reentry of CLZ into systemic circulation was not found in our time-course results (Fig. 3) and possible enterohepatic recycling of CLZ in man evidently has not been reported.
Wilk and Stanley (1978) also studied rat, using a gas chromatographic separation and electron capture detection to assay CLZ in brain tissue. They found that drug concentrations in corpus striatum and olfactory tubercle in this species rose in response to doses between $10 \mathrm{mg} / \mathrm{kg}$ and $60 \mathrm{mg} / \mathrm{kg}$, IP $(r=0.982)$ to similar concentrations in both brains region $(r=0.969$; mean ratio of CLZ in olfactory tubercle:striatum $=1.10$ ). Moreover, these levels did not increase at 1 hour after 12 days of repeated daily treatment at $20 \mathrm{mg} / \mathrm{kg}$ or 40 $\mathrm{mg} / \mathrm{kg}$ IP, compared to levels following a single administration (within $\pm 9.2 \%$ ). The concentration of CLZ in rat striatum averaged $36.5 \mathrm{nmol} / \mathrm{g}(11.9 \mu \mathrm{g} / \mathrm{g}$ vs. 13.8 in the present experiments) at 1 hour after a dose of $20 \mathrm{mg} / \mathrm{kg}$ IP. For striatal tissue at matched doses between $10 \mathrm{mg} / \mathrm{kg}$ and $60 \mathrm{mg} / \mathrm{kg}$ in both studies, levels of CLZ were in very close accord ( $r=0.985$, slope $=0.972$ ). These values thus compare well under similar conditions in both studies and also support the conclusion that CLZ does not accumulate in rat brain following repeated once daily treatment.

The concentrations of CLZ metabolites NOR and NOX found in the present study also can be compared to results of serum assays in clinical samples. In our recent clinical studies (Centorrino et al. 1993a, 1993b; Volpicelli et al. 1993), serum concentrations of CLZ averaged $235 \mathrm{ng} / \mathrm{ml}(0.719 \mathrm{nmol} / \mathrm{ml}$, or $\mu \mathrm{M})$ at approximately 16 hours after repeated daily doses averaging $300 \mathrm{mg}(4.3 \mathrm{mg} / \mathrm{kg})$ or about $54.7 \mathrm{mg} / \mathrm{ml}(167 \mathrm{nM})$ per $\mathrm{mg} / \mathrm{kg}$ dose. Concentrations of NOR averaged 206 $\mathrm{ng} / \mathrm{ml}$, and NOX averaged $54 \mathrm{ng} / \mathrm{ml}$, so that CLZ: NOR:NOX were found in the proportion 100:88:23. Another clinical report using powerful gas chromatographic-mass spectrometric assay methods found a similar ratio of $94 \%$ for NOR:CLZ in human plasma (Bondesson and Lindström 1988). These results compare with concentration ratios for CLZ:NOR:NOX in rat serum of 100:58:13 (using averaged data $[n=9$ conditions] for all doses of $10 \mathrm{mg} / \mathrm{kg}$ to $60 \mathrm{mg} / \mathrm{kg}$ and times up to 1 hour). The relationship of levels of NOR and NOX to dose of CLZ (Fig. 4) is consistent with their production by a saturable, and presumably enzymatic, process.

Comparison of the pharmacokinetics of CLZ and its major metabolites between human subjects and laboratory animals have been very limited. Times to peak plasma concentrations of CLZ in man have ranged from 30 minutes to 4 hours, and values for plasma elimination half-life of acutely administered CLZ have been reported to average about 8 hours to 12 hours (range, 6 hours to 33 hours; Baldessarini and Frankenburg 1991). However, its elimination half-life may increase somewhat after repeated daily dosing with CLZ, reportedly, from 8 hours to 14 hours (Choc et al. 1990). A positron-emission tomographic (PET) study in rhesus monkey using ${ }^{11} \mathrm{C}-\mathrm{CLZ}$ as a radioligand found evidence of minor regional differencesin 
drug concentrations in brain, and a similar elimination half-life from blood and brain, estimated at 4 hours to 5 hours (Hartvig et al. 1986). The present findings indicate that elimination rates for CLZ are similar in rat brain and serum (1.5 and 1.6 hours; Table 1 ) as they were from mouse blood and brain compartments (virtually completely eliminated within 4 hours of IV administration; Gauch and Michaelis 1970). These rates of elimination in rodents are considerably shorter than from human serum (approximately 8 hours; Choc et al. 1990) or in the nonhuman primate study just cited (approximately 4.5 hours). Values reported here ( $t y_{2}[\beta]$; Table 1) may underestimate "near-terminal" half-life (with late, low concentrations of drug), even with a relatively sensitive assay and good tissue recovery, although similar limitations due to assay sensitivity probably apply to other available estimates in animals and man. The evident lack of accumulation of CLZ (Wilk and Stanley 1978) or its metabolites (present findings) following a week or more of repeated daily administration of a large dose of CLZ is consistent with the relatively short elimination half-life observed for CLZ and its metabolites (Table 1).

One practical implication of the finding of very rapid elimination of CLZ and its metabolites from serum and brain in rodents is that studies using these species as pharmacologic models may fail to provide sustained, subtoxic, tissue levels of CLZ and its metabolic by-products unless the drug is given by repeated daily dosing, administration in drinking water, or by infusion.

A striking observation in the present study was that concentrations of CLZ in rat brain were much higher than in serum. Presumably, these results with corpus striatum represent events in other regions, based on evidence already cited that suggests limited differences in the distribution of CLZ between brain regions in rat (Wilk and Stanley 1978) or monkey (Hartvig et al. 1986). Previous studies of the brain: blood distribution of other antipsychotic agents in the rat have reported marked differences between specific agents (Tsuneizumi et al. 1992). Examples range from a relatively low brain:blood concentration ratio for thioridazine (1.4) or chlorpromazine (11.5) to higher values for haloperidol (22) and fluphenazine (31), but also for norchlorpromazine (23) and promazine (62.5). This ratio must reflect complex, and still largely unpredictable, relationships among free plasma concentrations of drug, lipophilicity and ability to penetrate the blood-brain barrier, affinity to cerebral components including lipid and membrane fractions, and rate of further local and systemic metabolic conversion and elimination. The tendency of the brain:blood ratio of CLZ to rise with dose, as we found (see analysis of Fig. 5: Results), also is not readily explained, but may suggest some sequestration of drug in brain tissue to limit its systemic metabolism and clearance.
Finally, other present findings concerning interactions between CLZ and pretreatments with fluoxetine or valproate show some parallels to recent clinical observations on such drug-drug interactions (Callahan et al. 1993), as well as some apparent differences. Fluoxetine markedly increased serum (and tended to increase brain) concentrations of CLZ and its metabolites and their sum in the rat, as we also found in serum of similarly treated patients (Centorrino et al. 1993b). This observation is consistent with other evidence suggesting that this agent can interfere with the oxidative metabolism and increase circulating concentrations of several psychotropic and other agents including tricyclic antidepressants (Ciraulo and Shader 1990; Callahan et al. 1993) and, to a lesser extent, haloperidol (Goff et al. 1991; Goff and Baldessarini 1993). Recent clinical case reports indicate that cotreatment with phenytoin was associated with decreased serum concentrations of CLZ and loss of clinical benefit (Miller 1991). After a week of pretreatment of rats with phenytoin (10 mg/kg/day; pilot data not shown), we found trends toward small decreases in levels of CLZ (by $24.8 \%$ and $26.6 \%$ in serum and brain), increased NOR in serum (2.12-fold), and a significant increase in the NOR:CLZ ratio (3.34-fold, $p<.05$ ), suggesting more efficient $\mathrm{N}$-dealkylation of CLZ. Pretreatment of rats with valproate (Fig. 6) led to a somewhat greater reduction of CLZ concentration (by $58.5 \%$ and $54.4 \%$ in serum and brain), with little change in NOR $(5.8 \%$ lower than control in serum), but an elevation of the NOR:CLZ ratio (by 3.68 -fold, $p<.003$ ). This observation suggests that valproate may have an oxidaseinducing action in the rat similar to that known to be associated with treatment by phenytoin and several other anticonvulsants (Williams 1989; Callahan et al. 1993). This effect of valproate was not expected because, in human subjects given this combination of agents, we recently found moderate increases in serum levels of CLZ (by 39\%) and a slight decrease of NOR (23\%), with a significant decrease (by $46 \%$ ) in their ratio; however, these effects were at least partly dose dependent and virtually disappeared when levels of CLZ plus its metabolites were corrected as the ratio to milligram per kilogram daily dose of clozapine (Centorrino et al. 1993b). To some extent, higher doses of CLZ may be associated with clinical use of valproate to avoid the reportedly dose-dependent risk of seizures associated with CLZ (Baldessarini and Frankenburg 1991; Devinsky et al. 1991). Other work also suggests that although valproate can interact with the disposition of some agents in man, it tends to do so less than most other anticonvulsants and (opposite to agents such as phenytoin) typically tends to induce minor elevations of their concentrations (Bourgeois 1988).

Overall, we conclude that (1) the laboratory rat can be employed usefully to model many aspects of the 
distribution, metabolism and elimination of CLZ: (2) it is likely, albeit from still limited comparative research, that species differences occur in the metabolism and elimination of CLZ and in interactions of other agents with CLZ; (3) there is a close correlation between brain and circulating concentrations of CLZ, with little NOR or NOX in brain, and these findings may be relevant to the interpretation of clinical assays of circulating CLZ; (4) elimination of this agent and its prominent metabolite NOR in rat brain is sufficiently rapid as to require repeated daily dosing or continuous infusion to sustain tissue concentrations of drug in the rat.

\section{ACKNOWLEDGMENTS}

Supported, in part, by USPHS (NIMH) grants and awards MH-14275, MH-31154, MH-34006, MH-47370, an award from the Bruce J. Anderson Foundation, and a Neuroscience Fellowship of Massachusetts General and McLean Hospitals. Clozapine and authentic standard samples of its metabolites were generously provided by the Sandoz Research Institute of Berne (where Dr. Baldessarini occasionally consults in preclinical neuropharmacology); fluoxetine was generously provided by Eli Lilly Labs. Suzann M. Babb, Ken Giannino, Hanna Konieczna, Nora S. Kula, and Elda R. Marsh provided valuable technical advice and assistance.

\section{REFERENCES}

Baldessarini RJ, Frankenburg FR (1991): Clozapine, a novel antipsychotic agent. $\mathrm{N}$ Engl J Med 324:746-754

Bondesson U, Lindström LH (1988): Determination of clozapine and its $\mathrm{N}$-desmethylated metabolite in plasma by use of gas chromatography-mass spectrometry with single ion detection. Psychopharmacology 95:472-475

Bourgeois BFD (1988): Pharmacologic interactions between valproate and other drugs. Am J Med 84:29-33

Callahan AM, Fava M, Rosenbaum JF (1993): Drug interactions in psychopharmacology. Psychiatry Clin North Am (in press)

Centorrino F, Baldessarini RJ, Kando J, Frankenburg FR, Volpicelli SA, Flood JG (1993a): Clozapine and metabolites: Serum concentrations and clinical findings during treatment of chronically psychotic patients. J Clin Psychopharmacol (in press)

Centorrino F, Baldessarini RJ, Kondo J, Frankenburg FR, Volpicelli SA, Puopolo PR, Flood JG (1993b): Serum concentrations of clozapine and its major metabolites: Effects of cotreatment with valproate or fluoxetine. Am J Psychiatry (in press)

Choc MG, Hsuan F, Honigfeld G, Robinson WT, Ereshevsky L, Crismon ML, Saklad SR, Hirschowitz J, Wagner R (1990): Single- vs multiple-dose pharmacokinetics of clozapine in psychiatric patients. Pharmaceut Res 7:347-351
Ciraulo DA, Shader RI (1990): Fluoxetine drug-drug interactions: Antidepressants and antipsychotics. J Clin Psychopharmacol 10:48-50

Cohen BM, Tsuneizumi T, Baldessarini RJ, Campbell A, Babb S (1992): Differences between antipsychotic drugs in persistence of brain levels and behavioral effects. Psychopharmacology 108:338-344

Devinsky O, Honigfeld G, Patin J (1991): Clozapine-related seizures. Neurology 41:369-371

Gardiner TH, Lewis JM, Shore PA (1978): Distribution of clozapine in the rat: Localization in lung. J Pharmacol Exp Ther 206:151-156

Gauch R, Michaelis W (1970): The metabolism of 8-chloro11-(4-methyl-1-piperazinyl)-5H-dibenzo[b,e][1,4]-diazepine (clozapine) in mice, dogs and human subjects. Il Farmaco 26:667-681

Goff D, Baldessarini RJ (1993): Interactions of drugs with antipsychotic agents. J Clin Psychopharmacol 13:57-67

Goff DC, Midha KK, Brotman AW, Waites M, Baldessarini RJ (1991): Elevation of plasma concentrations of haloperidol after the addition of fluoxetine. Am J Psychiatry 148:790-792

Haring C, Fleischhacker W, Schett P, Humpel C, Barnas C, Saria A (1990): Influence of patient-related variables on clozapine plasma levels. Am J Psychiatry 147:1471-1475

Hartvig P, Eckernäs SÅ, Lindström L, Ekblom B, Bondesson $\mathrm{U}$, Lundqvist $\mathrm{H}$, Halldin $\mathrm{C}$, Någren $\mathrm{K}$, Långström $\mathrm{B}$ (1986): Receptor binding of $\mathrm{N}$-(methyl- $\left.{ }^{11} \mathrm{C}\right)$-clozapine in the brain of rhesus monkey studied by positron emission tomography (PET). Psychopharmacology 89:248252

Kane JM, Cooper TB, Sachar EJ, Halpern FS, Bailine S (1981): Clozapine: Plasma levels and prolactin response. Psychopharmacology 73:184-187

Miller DD (1991): Effect of phenytoin on plasma clozapine concentrations in two patients. J Clin Psychiatry 52: 23-25

Perry PJ, Miller DD, Arndt SV, Cadoret RJ (1991): Clozapine and norclozapine plasma concentrations and clinical response of treatment-refractory schizophrenic patients. Am J Psychiatry 148:231-235

Simpson GM, Cooper TA (1978): Clozapine plasma levels and convulsions. Am J Psychiatry 135:99-100

Szymanski S, Lieberman JA, Picou D, Masiar S, Cooper T (1991): A case report of cimetidine-induced clozapine toxicity. J Clin Psychiatry 52:21-22

Tsuneizumi T, Babb SM, Cohen BM (1992): Drug distribution between blood and brain as a determinant of antipsychotic drug effects. Biol Psychiatry 32:817-824

Volpicelli SA, Centorrino F, Puopolo PR, Kando J, Frankenburg FR, Baldessarini RJ, Flood JG (1993): Determination of clozapine, norclozapine, and clozapine- $\mathrm{N}$-oxide in serum by liquid chromatography. Clin Chem (in press)

Wilk S, Stanley M (1978): Clozapine concentrations in brain regions: Relationship to dopamine metabolite increase. Eur J Pharmacol 51:101-107

Williams DA (1989): Drug metabolism. In Foye WO (ed) Principles of Medicinal Chemistry. Philadelphia, Lea \& Febiger, pp 79-117 